\title{
Comment
}

\section{Territorial Need Indicators: A Reply}

\section{A. C. BEBBINGTON* and BLEDDYN DAVIES +}

We are delighted to see the comment by Doreen Irving. In one of our papers we have argued that when used to assess Grant Related Expenditures (GRE), we expect (and hope) that the approach will be 'a Trojan horse wheeled into what Foster et al. (1980, p. 4) called "the mystery of mysteries", the calculation of Rate Support Grant' (Davies 1982). Our only regret is that Irving raises too many hares for us to identify and catch all of them.

\section{THEORY AND ESTIMATION}

Irving correctly asserts that we believe that a framework clearly based on a general theoretical argument can best focus research and debate so as to improve indicators. Irving suggests that theory constrains solutions, making it more difficult to produce those which will satisfy organized interests. She may be right, but we believe that to be politically acceptable is not enough. However, we would deny that our approach does not go to great pains to attempt to achieve a 'degree of elaboration of theory and method' which is 'carefully tailored to match existing knowledge' (Irving, 1983, p. 242). Of course, we also believe that it is partly the function of the theory we apply to focus the argument and research which develops knowledge.

So the relationship between theory and estimation is a theme we must clarify. By theory, we mean two types of argument. One is a body of theory at a high level of generality about the kind of factor which should be taken into account in the cost-benefit concept of need; meta-theoretical argument like economic theory, substantially independent of context and evidence about causal processes in specific circumstances. The second is theory about cause and effect in a particular context, and which throws light on the consequences of alternative interventions.

- Research Fellow, Personal Social Services Research Unit, University of Kent.

+ Professor of Social Policy, and Director of the Personal Social Services Unit, University of Kent. 


\section{Meta-theory}

Our ideas about the first kind of theory have been developed in a substantial number of papers. These provide the meta-theoretical context in which the second part of our 1980 paper can be understood. We are not referring to papers and books published from 1963 onwards and typified by the three books in the territorial justice trilogy (Davies, 1968: and Davies et. al. 1971; 1972), but to published work appearing since 1973, such as Davies (1974; 1975; 1976a; 1976b; 1976c; 1976d; 1977a; 1977b) and Bebbington and Davies (1980a, b). Many of these are referenced in the 1980 paper (p. 434, n. 3 ).

It is stated in the second part of the 1980 paper that what is possible with existing data sets is but a pale reflection of (a) what the metatheoretical framework demands and (b) what it would be possible to compute given data collections designed around the requirements of the meta-argument (p. 434). These requirements are alluded to in several of the theoretical papers. Basically, the difference between what has been feasible given existing data sets and what would be feasible in data sets designed to reflect the framework amount to the difference between (i) basing assessment judgements on estimates made by applying assumptions about service packages to the circumstances of persons, what we call the Mark II approach; and (ii) basing assessments on estimates of the implications of choosing alternative sets of ends (given budget constraints and views about the feasibility of alternative means in different circumstances) for the selection of service packages, given that services are substitutable and that their relative prices vary between areas, what we call the Mark III approach. We need hardly argue what a great advance the Mark III approach would be as a framework of estimates to combine with focused judgements. The only way of assessing its practicality in the foreseeable future is to collect the data it needs as best we can, attempt the estimation, and scrutinize the methods and results. It is only now that we have had sanction to design the first survey needed to provide data for the Mark III approach. There was no question of being able to use the data available in 1978 or 1979 to fashion Mark III indicators.

So it is unfortunate that Irving's critique pays no attention to these earlier (and subsequent) papers. It is not in the 1980 paper that we 'expound' the 'theory of needs judgements'. That paper provides only an introductory note to an exemplification designed to show the implications of assumptions of different kinds for estimates made within the constraints of available data. 
Substantive Theory

Our modular Mark II approach is intended to focus debate on investigated and researchable issues which are the focus of some of the main judgements made at all levels in allocating resources in social care. The relevant literature discussing argument and evidence is vast. Certainly relevant are, for instance, almost any explanatory analyses of 'territorial injustice', studies of 'need', investigations of cost and production relations in social care (particularly the estimation of 'territorial' cost functions), studies of the 'balance of care' and the substitutability of services in various circumstances, research on factors constraining the choice of techniques by authorities, investigations of sectoral mix regulatory policy and of variations in the availability of informal support and care. Nothing requires the advance and synthesis of such strands as urgently as the PSSRU approach to needs indicators.

Irving remarks that some of the variables used in synthetic estimation lack a 'logical' - that is, presumably, theoretically established - connection with judgements about the needs for services, and wrily comments that 'considering the importance which Bebbington and Davies attach to theory their empiricism in choosing census variables is remarkable' (1983, p. 244). A particular advantage of a theoretically based approach is that it displays lacunae in available indicators, and, moreover, provides the basis for deciding how they should be replaced. By this method strong and precise arguments were developed for including numbers of housebound elderly people living alone as a social indicator from the National Dwelling and Housing Survey for use in GRE formulae. Moreover, theory provides criteria by which the validity of the synthetic estimators can be tested. As new data sets become available, it is possible to check the accuracy of prediction. For example, Bebbington (1982) used previously derived formulae to predict target group sizes within the General Household Survey on a regional basis. The results were consistent with direct estimates from the General Household Survey.

\section{THE RATE SUPPORT GRANT}

\section{Centralist assumptions}

Irving rightly suggests that the estimation of GRE reflects the PSSRU approach. She suggests that local authority priorities might differ from those of central government but argues that the mis-match between local assumptions and central assumptions contradicts the apparent 'rationality' - whatever that is - of the formula.

We must not forget the purpose of need assessment. The Layfield 
Committee (1976) and the proposals of successive governments make it clear that it is not to finance differences in the priorities local authorities give to their public and other expenditures. To quote a Labour government's green paper, needs assessments:

... must account for variations between authorities in ... (a) the number and type of people who require particular services...(b) the amount of economic resources required to provide a comparable standard of services... (c) the relative prices of the resources required... (Cmnd 6813, 1977, p. 30).

Moreover, the procedures allow the authorities to articulate argument and mobilize evidence to develop the formula. It may not be widely known that the formula is developed by working groups whose members are representatives of local as well as central government. The groups attempt by $a$ priori argument and the assessment of evidence to agree a single acceptable formula. Issues are raised by each set of partners. Indeed, the effects of the subgroups seem to have largely been devoted to formulating and examining ideas raised by representatives of the local authority associations and considering alternative methods of adopting the formula to take others into account. This process is not one of making central government judgements.

\section{Judgements and the Rate Support Grant}

We think that Irving poses the questions involved in the choice of judgements in a way which does little to advance the argument. Is it not more sensible to ask how much difference making one assumption rather than another makes than it is to make obvious and highly general criticisms of the assumptions presented? We prefer to ask whether the results, the pattern of variations in assessed expenditure needs, are sensitive to variations in assumptions. We believe this is the useful question to ask about such questions as how many target groups to define (Irving, 1983, p. 243; the choice of package of service with greater or lesser constraint on resources in relation to needs; the choice of priorities accorded to different target clienteles among the elderly, or the selection of methods of intervention among alternatives of similar cost Some such issues of sensitivity were explored in an unpublished report (Bebbington and Davies, 1979). Correlation coefficients between some of the alternatives were referred to in the 1980 paper though these were not presented.

Some of Irving's criticisms seem to us to relate to the nature of the hypothetical world postulated for the exemplification, not to the way the approach would be used in practice. They are not therefore criticisms of the approach as such. An example is the criticism of the exemplification 
assumption that the distribution of total spending between services would be the same in 1980 as in 1975 . In any practical use, the assumption made would reflect an actual intention.

\section{CONCLUSION}

We are glad to see interest in this topic. It is vital that there should be informed discussion to help improve judgements and focus research. Doreen Irving is to be thanked for initiating what could be a most valuable stimulus to academic and policy development.

\section{REFERENCES}

A. C. Bebbington (1982), 'Using the 1980 GHS to Assess Need in Local Authorities', in Department of Environment report LGF(G) (PSS) (82)7.

A. C. Bebbington and B. Davies (1979), 'Territorial Need Indicators: A New Approach', Personal Social Services Research Unit Discussion Paper 108, University of Kent, Canterbury, Kent.

A. C. Bebbington and B. Davies (1980a) 'Territorial Need Indicators, A New Approach', Journal of Social Policy, Part 1, 9:2 (April) 145-68; Part II, 9:4 (October), 433-62.

B. Davies (1968), Social needs and resources in local services, Michael Joseph, London.

B. Davies (1974), 'Standard setting in the theory of social planning' in Social Affairs; report of the Expert Group and Standard setting in Social Welfare, SOA/ESDP/94/2. European Social Development Programme, United Nations, New York, 58-80.

B. Davies (1975), 'Causal process and techniques in the modelling of policy outcomes', in K. G. Young (ed.) Essays of the Study of Urban Politics, Macmillan, London, 7-57.

B. Davies (1976a), 'Determinants of variation in social services expenditures and the measurement of need', in Layfield (1976). Appendix 10.

B. Davies (1976b), 'The Personal Social Services' in B. P. Davies and G. J. Murray, Personal Social Services and Voluntary Organisations in the Personal Social Services Field, Reviews of United Kingdom Statistical Sources vol. 1, Heinemann, London, 7-57.

B. Davies (1976c), Census counts and need indicators for Social Services Departments, Social Services Research Group occasional paper no. 1, Chester.

B. Davies (1976d), 'The measurement of needs and the allocation of grant', in Layfield (1976), Appendix 10.

B. Davies (1977a), 'Needs and Outputs' in H. Heisler (ed.) Fundamentals of social administration, Macmillan, London, 129-162 and 237-40.

B. Davies $(1977 \mathrm{~b})$, 'Social services studies and the explanation of policy outcomes', Policy and Politics, 5:3, 41-61.

B. Davies (1982), "Assessing the spending needs of British local authorities for social care services: a new approach and its implementation', Personal Social Services Research Unit Discussion Paper 238, University of Kent, Canterbury, Kent.

B. Davies, A. Barton, I. S. McMillan and V. K. Williamson (1971), Variations in Services for the Aged: a causal analysis, Bell, London.

B. Davies, A. Barton, I. S. McMillan (1972), Variations in Children's Services among British Urban Authorities, Bell, London.

C. D. Foster, R. Jackman, M. Perlman (1980), Local Government Finance in a Unitary State, George Allen \& Unwin, London.

Cmnd. 6813 (1977), Local Government Finance (Green Paper), HMSO, London.

Doreen Irving (1983), 'Territorial need indicators: a comment', Journal of Social Policy, 12:2 (April), 241-5.

Layfield Committee Report (1976), Local Government Finance, Cmnd. 6453, HMSO, London. 